\title{
Research on the Interaction of Issues and Frames in University Public Opinions
}

\author{
Xiuxiu Tian \\ School of Xi'an Peihua university, Xi'an,710125,China
}

\begin{abstract}
The research focuses on the issues and frames interaction characteristics between media microblogs, opinion leaders' microblogs and netizens microblogs in the public opinion events of universities. Taking Liang Ying's academic misconduct as the case, and the content analysis method is used to quantitatively analyze the issues and frames. The study found that the media microblogs in telling the public what to think about - the factual issue setting is still valid; but in telling the public what to think - the attribute agenda setting and the framing have limited effect and more constraints. In the later stages of public opinion development, opinion leaders and netizens are significantly relevant in the discussion of attribute issues and the use of frame. Both can provide information sources and issues for the media microblogs, but it is difficult to truly achieve the media agenda setting.
\end{abstract}

Keywords: University Public Opinions; issues interaction; frame selection; content analysis.

\section{Introduction}

Weibo is the core platform for online public opinion communication in China. According to the "China Network Social Mentality Survey Report", the issue of higher education is the topic with the highest rate of mention among Weibo netizens (ZHENGN, GUI, HUANG, 2017) [1]. The Weibo platform can visually present the connections, interactions and influences between different expression subjects in public opinion events, and reveal the powers and factors that influence public opinion. The analysis of the interaction between the media, opinion leaders and netizens in university public opinion event on the Weibo platform will help to understand and grasp the laws of public opinion and promote the guiding public opinion.

\section{Research Design and Method}

The problem of academic misconduct in universities is a hot topic in public opinion in recent years. This paper takes Liang Ying's academic misconduct as a typical case, and uses content analysis to examine the connection, interaction and influence between the media microblogs, opinion leader microblogs and netizen microblogs about the issue and frame.

The content analysis unit of this research is a single microblog. The study used "Liang Ying" as the key word, focused on the full-text search of the Weibo platform in the public opinion outbreak-diffusion-dissipation period, obtained 4,791 microblogs. The final study samplied the most influential 100 media microblogs, 100 opinion leader microblogs, and 200 netizen microblogs, and drawn a sampling microblogs public opinion diffusion map. It is consistent with the diffusion curve of the event on the Weibo platform, indicating that the sample is representative. The two coders independently coded the microblogs type, theme, frame and frame definer. The Cohen's Kappa coefficient exceeded 0.80 . The coding reliability was good, and the data was statistically analyzed using Excel and SPSS20.0.

\section{Interaction of Issues}

Interaction of issues: The media is the main provider of factual issues. Opinion leaders and netizens supplement the issues by breaking the news and diversify the issues through value judgments.

The issues interaction refers to the process of issues exchange and mutual influence between different subjects in the spread of public opinion. This study examines the issue ordering of three 
types of subject and the quantitative correlations. It is found that the issue of the media, opinion leaders and netizens have some commonalities, but the issue rankings are different.

\subsection{Media is the Main Setter of Factual Issues, But it cannot Lead the Discussion of Attribute Issues of Opinion Leaders and Netizens.}

In the spread of the public opinion, the media microblogs such as the paper, li videos, Weibo headlines and other media timely reported the core facts such as academic misconduct, teaching and research attitudes, academic ethics, and event processing, which formed a resonance between the media. And the media setted core factual issues for the vast majority of opinion leaders and netizens on the Weibo platform. Through the ranking and correlation analysis of the attribute issues discussed in the three different types of subjects, it is found that the attribute agenda of the media has not been transferred to the opinion leader and netizens. The relevance of the media attribute agenda to the opinion leader attribute agenda is not significant $(\mathrm{p}>0.05)$, and The relevance of the media attribute agenda to the public attribute agenda is not significant $(p>0.05)$. It can be seen that in the spread of public opinion, the media microblogs scroll the objective facts and can still form a guide to the core factual issues of the event. However, opinion leaders and netizens are concerned about the diversification of content and have the ability to derive issues (GANLU,2003) [2]. They are not limited to the factual issues provided by the media. In the public opinion, media microblogs cannot fully dominate the attribute issues of the event.

The data showed a significant correlation between the opinion leader attribute agenda and netizens attribute agenda $(p<0.05)$. In the spread of public opinion, opinion leaders are more active in the face of information dissemination. They are not only the intermediary of media factual information, but also the providers of opinions, focusing on the issues of academic fraud, the status of academic supervision, and the evaluation mechanism of teachers. It is easy to form a relationship with a diversified netizens microblogs.

\subsection{Opinion Leaders and Netizens Set the Issue for Media by Breaking the News, and Diffuse Event Attribute Issues Through Value Judgments.}

In the spread of public opinion, opinion leaders set the issue for media by breaking the news. On December 12th, opinion leaders @ Intellectuals (150,000 fans), well-known financial broadcasters (a)CHINSES LIUJIE (fans 1.96 million) took the lead in breaking the picture of Nanjing University's opinion on Liang Ying, causing other netizens forwarding. Finally, the media such as LI Video was promoted to Nanjing University to verify the facts. Nanjing University announced the results on its official news website on December 15. It can be seen that opinion leaders and netizens have promoted media and Nanjing University reports on the factual issues of processing results. They setted media issues. The role of opinion leaders in setting up issues for the media is inseparable from the power of netizens, forming a path of opinion leaders-netizens-media issues.

In the spread of public opinion, netizens will judge the one-sided information based on their own knowledge, experience and values, and publish opinions with inclinations (CHEN, WANG, WANG, 2011) [3]. On the Weibo platform, opinion leaders and netizens often combine discourse with "what to think about" and "what to think". They will capture the core elements of the media and capture the fragment elements in the event. They contact the same type of events, phenomena, and the regulatory and evaluation mechanisms behind the mining events. Through value judgments, they make the issues not limited to the events themselves, resulting in the diffusion of sensational issues. However, their issues such as supervision and evaluation mechanisms have not been translated into media issues. To a certain extent, it is difficult to set media value judgment issues.

\section{Interaction of Frame}

Interaction of frame: the three types of subjects are more inclined to adopt their own defined frame; Late stage of public opinion, opinion leaders and netizens are more likely to generate frame resonance 
In the spread of public opinion, the media, opinion leaders, and netizens all try to define events in their own way, propose a frame for understanding events, and become a frame definer. They selectively perceive certain parts of the event and highlight them in the text, thereby achieving definitions of the problem, causal explanations, moral judgments, and suggestions.

\subsection{The Three Types of Subjects are More Willing to Adopt Their Own Defined Frame, and There is a Certain Degree of Frame Flow.}

From the data point of view, the media, opinion leaders, and netizens have significant differences in adopting the frame $\left(\mathrm{X}^{2}=328.336, \mathrm{df}=8, \mathrm{p}<0.001\right)$. All three tend to use their own defined frame, and the proportion of data is respectively $45 \%, 55 \%$, and $70.5 \%$. The media microblogs has adopted the frame defined by opinion leaders in a small scope $(5 \%)$, and its frame is also cited by opinion leaders $(20 \%)$ and netizens $(14 \%)$. It can be seen that different subjects are more willing to use their own defined frames, but a small number of mutual reference frames between different subjects also indicate that Weibo public opinion has a certain frame flow and the nature of open discussion.

\subsection{The Media Focuses on the Problem Definition Frame, and the Opinion Leaders and Netizens Frame are Diverse.}

The media frame is more concentrated, $90 \%$ adopt the problem definition frame, $1 \%$ causal interpretation frame, $2 \%$ treatment recommendation frame, and $7 \%$ moral evaluation frame. The inter-media issue interaction process makes it easier to adopt a homogeneous frame and report similar incidents with similar positions and methods (LIU, CHANG, 2017) [4]. In this public opinion spread, different media microblogs are dominated by the problem-defining frame to fragment the dissemination of factual information.

The opinion leader and netizens frame using are more diverse. $52 \%$ of opinion leaders use the factual problem definition frame, and another $48 \%$ adopts a value judgment frame such as causal interpretation, moral evaluation, and treatment recommendation. In the spread of public opinion, opinion leaders are superpositions of dual roles. They are both communicators of factual information and interpreters of opinions, providing clear attributions and suggestions in fragmented information. Netizens uses the most moral evaluation frame (39.5\%). It reflects the public's dislike of academic misconduct. And it also reflects the basic characteristics of moral and emotional judgment when the public participates in the discussion. At the same time, netizens has adopted the frame of problem definiting (33\%), causal interpretation $(21.5 \%)$, and treatment recommendation $(6 \%)$ to rationally define and discuss the event, indicating that the public has a certain rational dialogue and communication ability in the spread of public opinion.

\subsection{In the Later Stage of Public Opinion Development, the Opinion Leader and Netizens Generated Frame Resonating, and the Public Opinion was Converging.}

To further study the correlation between the frames of the three types of subjects, this study divided three stages according to the development of public opinion: October 26-25, Liang Ying academic misconduct incident exposure stage; October 26-December 14 Event discussed stage; December 25 to 31 Event processing and public opinion dissipation stage. The researchers sorted out the specific subdivision frames used by the three types of subjects in the three stages and the overall public opinion dissemination, and tested the spearman correlation coefficient with significance.

In the three stages of diffusion, The frame correlation of the media to opinion leaders and netizens is not significant. However, in the third stage of diffusion, opinion leaders and netizens showed a resonance $\left(\mathrm{r}=0.840^{* *}, \mathrm{p}=0.002\right)$. Both of them are based on the factual definition and affirmative moral evaluation on the results of academic misconduct, and recommend to control the fraud and improve the academic supervision and system evaluation.

During the whole process of public opinion spread, the media microblogs try to define the problem in the factual academic misconduct, which limits the reflection and review of the root cause of the incident.Compared to the single frame of media microblogs, the multiple frames of opinion leaders are more likely to resonate with netizens. The influence of the opinion leader group in public events 
shows a situation of hierarchical communication, and the opinion leader group has a comprehensive impact on the network public opinion field through the frame differentiation (LU, YANG,2013) [5]. However, the causal interpretation and treatment recommendation frame used by opinion leaders and netizens did not adversely affect the media microblogs.

\section{Conclusions and Discussion}

In this public opinion communication, the media microblogs provide the vast majority of factual issues for the Weibo platform with a problem definition frame, telling the public what to think about, but telling the public what to think-what frame to use to understand the event is not so successful. Conversely, opinion leaders microblogs and netizens microblogs are relevant in the use of attribute issues and frame. Opinion leaders seem to be more influential in mediaizing what to think and use what frame to understand events.

One reason for this result is that most of the media microblogs use factual news as the main content, and the commentary is published less and not timely, so it can only output the impact on the factual issues and problem definition frame. Conversely, opinion leaders and self-media are some of the factual providers and major opinion makers on the Weibo platform. Their key breaking news, clear opinions and emotional expressions, unofficial identity, and more frequent interactions with netizens, even the views cater to the public, makes their opinions are often resonating with the public.

The second reason is that the attribute agenda setting and the framing are a complex process. Entman pointed out that the frame has at least four shelters: communicators, texts, recipients and cultures, and the framehas to undergo a process of experience from the communicator-textrecipient's contemporary psychosocial-recipient expression. There are many factors influencing the diffusion effect of the framing between different subjects, and there are many constraints. The frame correlation between opinion leaders and netizens also mainly occurs in the third stage of the spread of public opinion. In fact, with the deepening of the flow of opinions on the Weibo platform, consensus between opinion leaders and netizens can be reached.

The "limited interaction" between media microblogs and opinion leaders and netizens also reflects the difficulty of public opinion as a media input mechanism. To what extent the public voice and frame are absorbed by the media, the initiative is still in the hands of the media, and the media's own operational management mechanism is the core leading force in the media agenda. The group of people who broke the news is the group that participates in the media agenda construction, but the real realization of the agenda setting for the media also requires strict judgment and selection by the media. This selection is not determined by the amount of information that is broken, depending on the positioning and media frame of each media organization (WANGXIAOHUA,2010) [6]. However, in the new media era, We should also see whether public opinion affects the media agenda may not be that crucial. Public voices and opinions can also cross the media agenda and be directly noticed by administrative managers. As far as academic misconduct is concerned, the Ministry of Education has introduced some policies to strengthen academic integrity and academic supervision, and to guide the change of the talent evaluation mechanism in a guiding manner.

\section{Acknowledgements}

Fund: Special scientific research project of the Department of Education of Shaanxi Province , "Research on the Image Communication of Shaanxi University in the Network Age" (Project No.: 18JK1070). Scientific research project of Xi'an Peihua University, "Research on the Mechanism of Internet Public Opinion Eruption in Universities" (Project No.: PHKT19020).

\section{References}

[1]. Zheng Wen, Gui Yong, Huang Ronggui: "Looking for Internet Public Opinion: Research on the Mentality of Network Society", Huaxia Publishing House, 2017, p3. 
[2]. Ganlu: "Analysis of the Characteristics of the Network Agenda Setting", Chinese Journal of Journalism \& Communication, 2003, No. 4, p36-39.

[3]. Chen Qiang, Wang Yalei, Wang Guohua: "Study on the Generalization of Internet Public Opinions in College Emergencies", Journal of Intelligence, 2011, No. 5, p47-54.

[4]. Liu Lianlian, Chang Song: "The Interaction of Issues, the Formation of Public Opinion and the Paradox of Public Opinion--Reconstruction of the Guidance of Traditional Media's Public Opinion in the New Media Age", Academics, 2017, No. 3, p114-122.

[5]. Lu Heqiu, Yang Zeya: "Discourse Strategy and Text Frame of Weibo Opinion Leaders in Public Events - - An Empirical Study Based on Sina Weibo", Journal of Hubei University (Philosophy and Social Sciences), 2013,No. 5, p142-147.

[6]. Wang Xiaohua: An Empirical Study on the Situation of Reporters Participating in the Media Agenda, Journalism and Communication Research,2010, No.3, p28-34. 